\title{
Ulysses and the Sirens: a parable of the hard-liners of neurosurgery
}

\author{
Jean Claude Marchal
}

Published online: 22 July 2008

(C) Springer-Verlag 2008

Greek mythology tells no tale of the Neurosurgeon's Muse. Yet the history of Neurosurgery resounds with the voices of mermaids and their incantation on daredevil operative practices: complicated neurosurgery, complete neurosurgery and magical neurosurgery!

Who among us, whilst operating on a craniopharyngioma or hypothalamo-chiasmatic tumour (Fig. 1), has not felt, in the heat of the action, the deluding sentiment that anything is possible: the illusion of mind over matter? Whose hand has resisted the temptation of complete excision, the desire to eradicate those few cubic millimeters of tumour which could make all the difference between an operation with successful follow-up, and a clinical and biological catastrophe?
Ben Jonson [1] wrote:

"Knowledge, that sleeps, doth die;

And this Securitie,

It is the common Moath,

That eats on wits, and Arts, and oft destroyes them both."

Blind, is the child with dislocated memory, through our doing. Blind, also, was the rhapsodist

"Whose distant footsteps echo

Through the corridor of Time" [2].
Fig. 1 Pre operative MRI (a) and post operative CT (b) sagittal views of a pediatric hypothalamo-chiasmatic tumor. The post operative study demonstrates the complete removal of the lesion which required the excision of the infiltrated hypothalamus
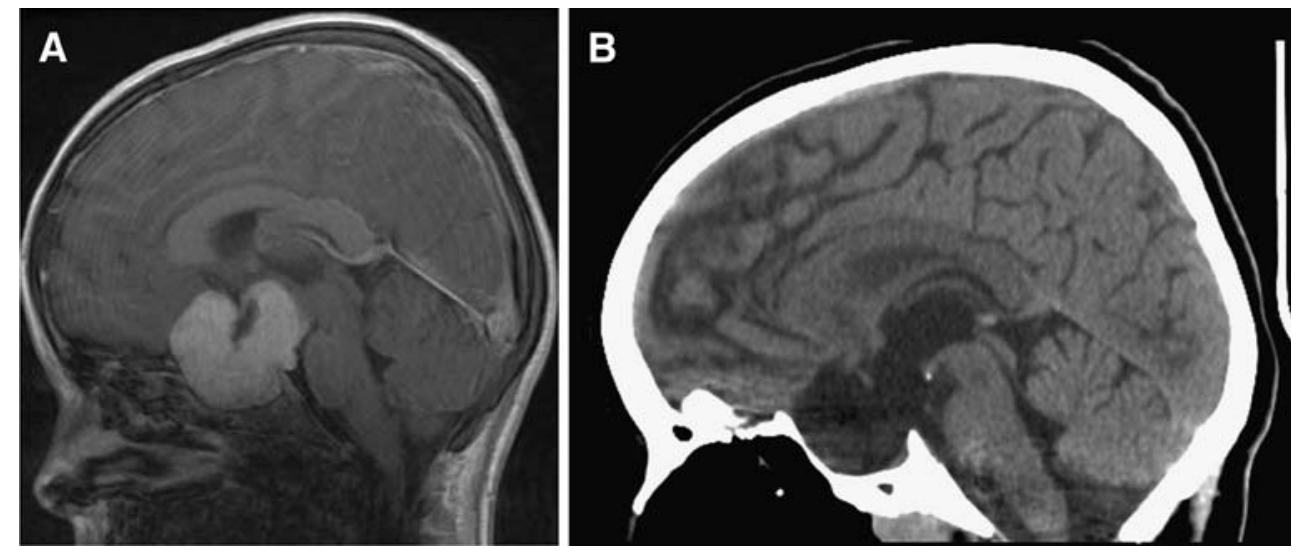

J. C. Marchal $(\bowtie)$

Unit of Pediatric Neurosurgery Central Hospital,

54035 Nancy cedex, France

e-mail: jc.marchal@chu-nancy.fr 


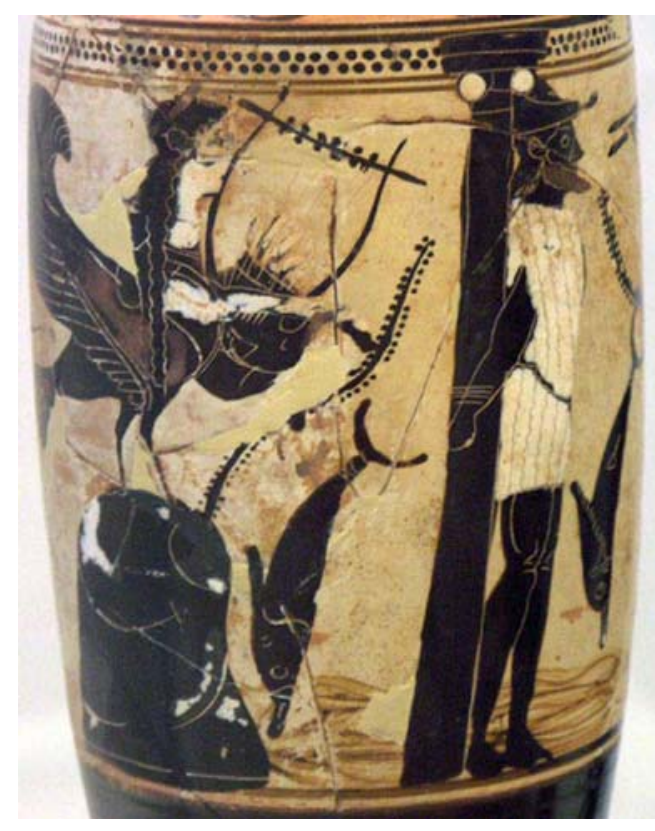

Fig. 2 Cover illustration
He tells us the tale of Ulysses' return to Ithaque, his courage during the bleak moments throughout the hardships of his voyage, his wisdom when he made himself tied to the ship's mast (Fig. 2) that he might resist the mermaid's chanting: "They sang these words most musically, and as I longed to hear them further I made by frowning to my men that they should me set free" [3].

There is no Muse for the Neurosurgeon, only mermaids that massage his ego. If there was a Muse, she would surely inspire us just as she inspired Ulysses' men, by pouring wax into our ears and tying up our hands.

\section{References}

1. Jonson B. An ode. To Himselfe

2. Longfellow HW. The day is done

3. Homer. The odyssey. Book 12. In: Butler S (ed) 